\title{
STAT3 enhances intracellular Fas-mediated apoptotic signals in HHUA human endometrial epithelial cells
}

\author{
TETSUJI TANAKA ${ }^{1}$, TAO BAI ${ }^{1}$, HIROTOSHI UTSUNOMIYA ${ }^{2}$, \\ TAKAHIRO FUKUMOTO ${ }^{3}$ and KAZUNORI YUKAWA ${ }^{4}$
}

\begin{abstract}
Departments of ${ }^{1}$ Obstetrics and Gynecology, and ${ }^{2}$ Experimental Pathology, Wakayama Medical University, Wakayama 641-0012; ${ }^{3}$ Research Center for Infection-Associated Cancer, Institute for Genetic Medicine, Hokkaido University, Sapporo 060-0815; ${ }^{4}$ Department of Physiology, Faculty of Pharmacy, Meijo University, Nagoya 468-8503, Japan
\end{abstract}

Received September 15, 2010; Accepted December 24, 2010

DOI: $10.3892 / \mathrm{mmr} .2011 .424$

\begin{abstract}
Several endometrial signal transducer and activator of transcription 3 (STAT3)-activating cytokines are reported to be essential for blastocyst implantation, with inhibition of STAT3 activation in the endometrium also reported to prevent implantation. To investigate STAT3 signals in endometrial epithelial cells, the activation and inactivation effects of STAT3 signals were examined in the human endometrial epithelial cell line HHUA, which is thought to retain many of the intracellular signaling pathways found in normal human endometrial epithelial cells. Five STAT3-activating cytokines, IL-11, IL-10, LIF, oncostatin M and leptin, enhanced the Fas-mediated apoptosis of the HHUA cells without any increase in cell surface Fas antigen expression. STAT3 siRNA transfection suppressed STAT3 expression in HHUA cells and significantly inhibited Fas-mediated cell death. These results indicate that intracellular apoptotic signals in HHUA cells are constitutively activated and regulated by STAT3-mediated signals. This apoptosis-promoting effect of STAT3 in HHUA cells is completely different from many previous reports demonstrating anti-apoptotic effects by STAT3 activation. The STAT3 signals in HHUA cells may be specific to the human endometrial epithelial cell lineage in the regulation of blastocyst implantation.
\end{abstract}

\section{Introduction}

Unlike most normal adult tissues, cyclic growth and tissue remodeling occurs within the uterine endometrium throughout the reproductive years. Tissue remodeling is regulated by a balance between cell growth and selective cell death (apoptosis). Apoptotic cells are found in normal human endometrial

Correspondence to: Dr Tetsuji Tanaka, Department of Obstetrics and Gynecology, Wakayama Medical University, 811-1 Kimi-idera, Wakayama 641-0012, Japan

E-mail: obgywmu@wakayama-med.ac.jp

Key words: signal transducer and activator of transcription 3, apoptosis, endometrium, implantation, Fas epithelium, and the number of endometrial apoptotic cells is reported to increase during the secretory phase of the menstrual cycle (1-3), the blastocyst implantation period. Fas-mediated apoptosis is thought to affect blastocyst implantation, since the Fas antigen, a cell surface apoptotic death receptor, is expressed in the pre-implantation human endometrial epithelium (4-6), and endometrial epithelial apoptosis occurs during blastocyst implantation $(7,8)$. Moreover, specific stimulation of Fas antigen induces the apoptosis of normal human endometrial epithelial cells $(6,9,10)$.

Recent studies in cytokine-null or receptor-null mice have revealed that several interleukin (IL)-6 family cytokines may play essential roles in blastocyst implantation and/ or endometrial stromal decidualization. Leukemia inhibitory factor (LIF)-null female mice exhibited impaired blastocyst implantation that can be partially restored by intraperitoneal administration of LIF (11). Additionally, transfer of recovered embryos from LIF-null mice to wild-type pseudopregnant female mice resulted in implantation and pregnancy. Female mice with a null mutation in the IL-11 receptor $\alpha$ chain are also reported to be infertile due to defective decidualization (12). Oncostatin M (OSM) binds competitively to the LIF receptor to regulate LIF functions on targeted cells, although the physiological functions of OSM in the human endometrium are not entirely understood (13). Both IL-11 and LIF bind to each specific receptor and activate signal transducer and activator of transcription 3 (STAT3), while specific inhibition of STAT3 activation in the endometrium prevents implantation (14). These results indicate that STAT3-activating cytokines may play important roles in human blastocyst implantation. The first step of blastocyst implantation is endometrial epithelial cell apoptosis following blastocyst attachment to the epithelium. Therefore, we examined the effects of STAT3activating cytokines on the Fas-mediated apoptosis of human endometrial epithelial cells.

In the present experiments, five STAT3-activating cytokines, LIF, IL-11, OSM, leptin and IL-10, were used. The leptin/leptin receptor system has been reported to be a regulator of the blastocyst implantation process (15). IL-10 is an anti-inflammatory cytokine expressed in the endometrium and placenta, although IL-10-null mice do not have impaired embryo implantation (16). In the present study, the HHUA 
human endometrial epithelial cell line was selected because the cells express high levels of Fas antigen as well as functional estrogen receptors and progesterone receptors, similar to the normal human endometrial epithelium during the implantation period (17), and form glandular luminal structures in collagen gel cultures, similar to the structures of normal glandular epithelial cells (18). Karyotyping analysis performed on 20 HHUA cells revealed normal 46XX karyotypes (19). HHUA cells are known to express functional Fas antigens on their cell surface that mediate specific apoptotic signals (9). Based on these characteristics, HHUA cells are considered to retain many of the intracellular signaling pathways found in normal human endometrial epithelial cells. Hence, in the present study, HHUA cells were used to examine the effects of five STAT3-activating cytokines on basic cellular functions, such as proliferation, viability and apoptosis.

\section{Materials and methods}

Cell line and culture. The HHUA cell line (17) was obtained from the Riken Cell Bank (Tsukuba, Japan). All cells in these experiments were cultured in OPTI-MEM (Invitrogen, Carlsbad, CA, USA) supplemented with $5 \%$ fetal bovine serum (Equitech Bio Inc., Ingram, TX, USA), penicillin (100 U/ $\mathrm{ml})$, streptomycin $(100 \mathrm{U} / \mathrm{ml})$ and fungizone $(0.25 \mu \mathrm{g} / \mathrm{ml}$; Invitrogen) in the presence of $5 \% \mathrm{CO}_{2}$ and $95 \%$ air at $37^{\circ} \mathrm{C}$.

Cell proliferation assay. The cell proliferation effects of human recombinant cytokines or mouse anti-human Fas monoclonal IgM (clone CH-11; MBL, Nagoya, Japan) on HHUA cells were measured. HHUA cells were seeded onto 96-well plates at $5 \times 10^{3}$ cells/well $(n=6)$ and incubated with various concentrations of recombinant human cytokines or anti-Fas IgM for $48 \mathrm{~h}$. At the end of the treatments, viable cell numbers were determined using a cell counting kit (Dojin Chemical Laboratory Co. Ltd., Tokyo, Japan) according to the manufacturer's instructions. The absorbance at $450 \mathrm{~nm}$ was measured using a microplate reader. A viability of $100 \%$ was defined as the absorbance obtained for cells without any treatment. All five STAT3-activating cytokines used in the cultures were purchased from PeproTech EC Ltd. (London, UK).

Cell viability assay. Cell viability was examined using the cell counting kit. The stimulatory effects of anti-Fas IgM (clone $\mathrm{CH}-11$ ) and one of the STAT3-activating cytokines on the cell viability of HHUA cells were assayed as follows: on day 1 , HHUA cells in the log phase were detached using $0.25 \%$ trypsin/1 mM EDTA (Invitrogen) and cultured overnight in 96-well plates $(5,000$ cells/well). On day 2 , combinations of anti-Fas IgM and one of the five STAT3-activating cytokines were added to the cells. On day 4 , the viable cell numbers were counted using the kit. The final concentration of recombinant human cytokines used in the culture media were $25 \mathrm{ng} / \mathrm{ml}$ for IL-11, IL-10, LIF and OSM, and $50 \mathrm{ng} / \mathrm{ml}$ for leptin.

DNA fragmentation assay. HHUA cells in the log phase were detached with $0.25 \%$ trypsin/ $1 \mathrm{mM}$ EDTA and cultured overnight $\left(3 \times 10^{6}\right.$ cells/dish). On day 2 , one of the five recombinant human cytokines was added to the cells for $1 \mathrm{~h}$, followed by the addition of anti-Fas IgM (final concentration, $75 \mathrm{ng} / \mathrm{ml}$ ). On day 4, genomic DNA was extracted from all cells, including dead cells, using a SepaGene DNA extraction kit (SankyoJunyaku Co. Ltd., Tokyo, Japan) and treated with $100 \mu \mathrm{g} / \mathrm{ml}$ RNase A (Sigma, St. Louis, MO, USA) in TE buffer $(10 \mathrm{mM}$ Tris, $\mathrm{pH} 8.0,2 \mathrm{mM}$ EDTA) for $90 \mathrm{~min}$ at $37^{\circ} \mathrm{C}$ to remove any contaminating RNA. Approximately $20 \mu \mathrm{g}$ of the genomic DNA was electrophoresed on a $1.2 \%(\mathrm{w} / \mathrm{v})$ agarose gel at $50 \mathrm{~V}$ for approximately $2 \mathrm{~h}$, stained with $5 \mu \mathrm{g} / \mathrm{ml}$ ethidium bromide and visualized by UV illumination. The final concentrations of recombinant human cytokines in the culture media were $100 \mathrm{ng} / \mathrm{ml}$ for IL-11, IL-10, LIF and OSM, and $200 \mathrm{ng} / \mathrm{ml}$ for leptin.

Semi-quantitative flow cytometry. HHUA cells were detached and re-cultured in dishes as described above. Untreated HHUA cells and HHUA cells treated with each cytokine for 2 days were detached from the dishes using $3 \mathrm{mM}$ EDTA in phosphate-buffered saline (PBS) and stained. Cells $\left(3 \times 10^{5}\right)$ were incubated with an excess of mouse anti-human Fas (CD95) monoclonal antibody (clone UB2; MBL) for $20 \mathrm{~min}$ at $4^{\circ} \mathrm{C}$, then washed twice with washing buffer (PBS containing $2 \%$ fetal calf serum and $0.1 \% \mathrm{NaN}_{3}$ ) and incubated with a secondary antibody [FITC-conjugated goat anti-mouse IgG (H+L); Dako-Japan, Kyoto, Japan] for $20 \mathrm{~min}$ at $4^{\circ} \mathrm{C}$. After two washes, the cells were suspended in $200 \mu \mathrm{l}$ of washing buffer and analyzed with a FACSCalibur ${ }^{\mathrm{TM}}$ (Becton Dickinson, Mountain View, CA, USA). The final concentrations of recombinant human cytokines in culture media were $100 \mathrm{ng} / \mathrm{ml}$ for IL-11, IL-10, LIF and OSM, and $200 \mathrm{ng} / \mathrm{ml}$ for leptin.

Transfection of STAT3 siRNAs. The STAT3 siRNA and the negative control siRNA were obtained from a SureSilencing ${ }^{\mathrm{TM}}$ Human STAT3 siRNA kit (SuperArray Biosci Corp., Frederick, MD, USA). Lipofectamine 2000 (Invitrogen) was used as the transfection reagent according to the manufacturer's instructions. For the experiments, cells were seeded onto 6 -well plates $\left(2.5 \times 10^{5}\right.$ cells/well $)$ or 10 -cm dishes $\left(2 \times 10^{6}\right.$ cells/dish), cultured for $24 \mathrm{~h}$ and then transfected with the STAT3 siRNAs or control siRNA. Subsequently, the cells were cultured for 72-120 h for protein assays before being harvested as indicated.

Western blotting. For Western blot analysis, the cells were collected at 72-120 h post-transfection with the STAT3 siRNAs or control siRNA, and lysed with PBS containing $1 \%$ NP-40, $0.1 \%$ sodium dodecyl sulfate, complete protease inhibitor cocktail (Roche Diagnostics Corp., Indianapolis, IN, USA) and $1 \mathrm{mM}$ phenylmethyl sulfonyl fluoride. The protein concentrations of the cell lysates were quantified by Coomassie Plus Protein assays (Pierce Biotechnology Inc., Rockford, IL, USA). Equal amounts of the total proteins were separated by SDS-PAGE using a $7.5 \%$ gel, and then transferred to a polyvinylidene fluoride membrane (ATTO Corp., Tokyo, Japan). After sequential incubations with primary and secondary antibodies, the immunocomplexes on the membranes were detected using enhanced chemiluminescence (ECL) or ECL plus kits (Amersham Pharmacia Biotech, Uppsala, Sweden). The antibodies used were mouse anti-human STAT3 monoclonal antibody (clone STAAD22A; Cosmo Bio Co., Ltd., Tokyo, Japan) and mouse monoclonal anti- $\beta$-actin antibody 
A

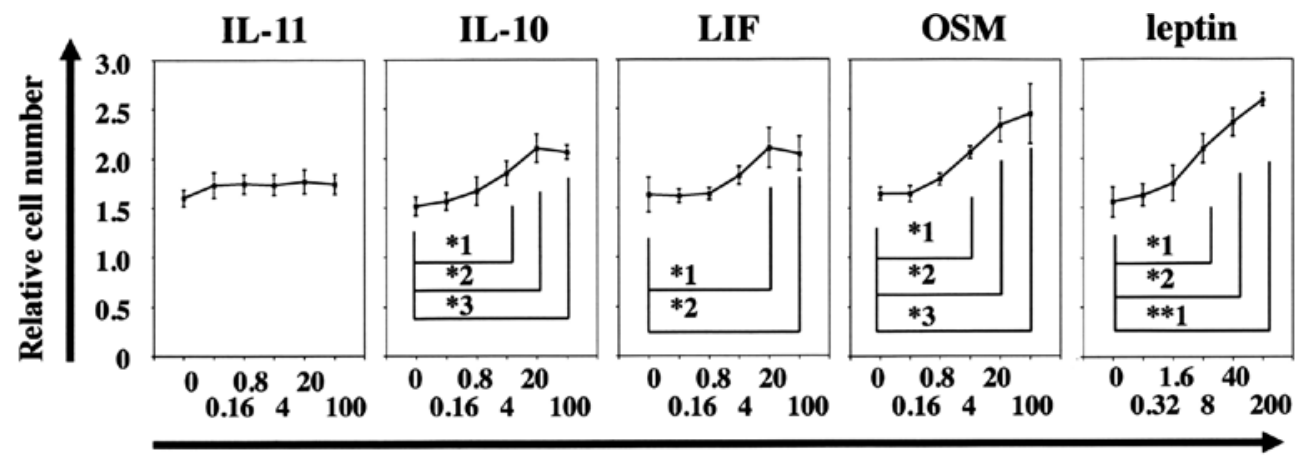

Cytokine (ng/ml)

B

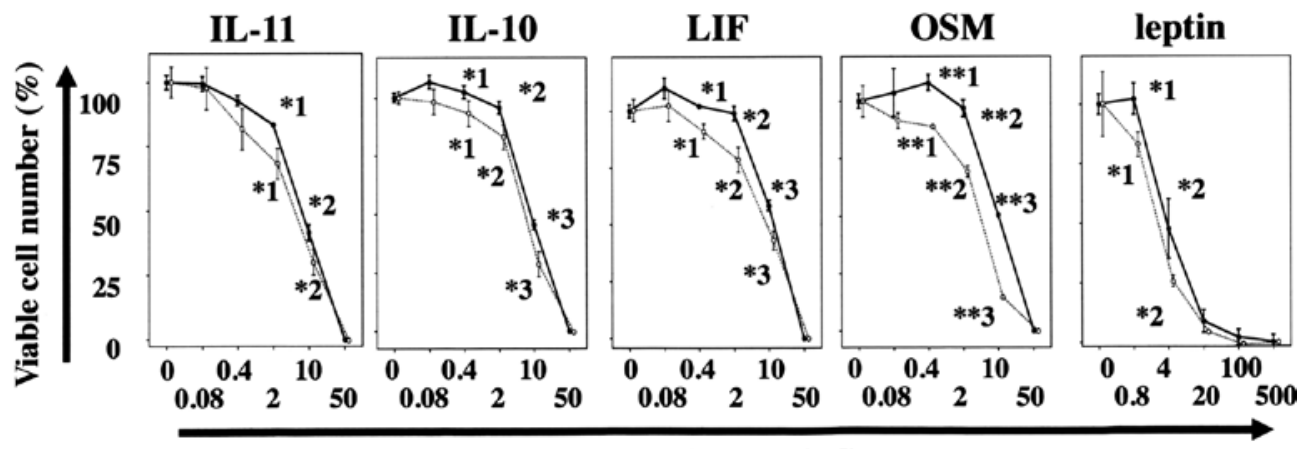

anti-Fas IgM (ng/ml)

Figure 1. Effects of STAT3-activating cytokines on the cell proliferation and Fas-stimulated cell death of HHUA cells. (A) Effects of STAT3-activating cytokines on the cell proliferation of HHUA cells. ${ }^{*} 1,{ }^{*} 2,{ }^{*} 3, \mathrm{p}<0.05 ;{ }^{* *} 1, \mathrm{p}<0.01$. (B) Effects of STAT3-activating cytokines on the Fas-stimulated cell death of HHUA cells. Cells were co-treated with anti-Fas IgM and a cytokine for 2 days. The final concentrations of the recombinant human cytokines were $25 \mathrm{ng} / \mathrm{ml}$ for IL-11, IL-10, LIF and OSM, and $50 \mathrm{ng} / \mathrm{ml}$ for leptin. ${ }^{*} 1,{ }^{*} 2,{ }^{*} 3, \mathrm{p}<0.05 ;{ }^{* *} 1, \mathrm{p}<0.01$.

(Sigma Chemical Co.). The membranes were stripped and reprobed with an anti- $\beta$-actin antibody.

Statistical analysis. Data were expressed as the means \pm SD. Comparisons between experimental groups were performed by analysis of variance (ANOVA). If the ANOVA was significant, post-hoc comparisons were conducted using Scheffe's test. The level of statistical significance was set at $\mathrm{p}<0.05$.

\section{Results}

Effects of STAT3-activating cytokines on cell proliferation and Fas-stimulated cell death of HHUA cells. First, the effects of the five STAT3-activating cytokines on the cell proliferation of HHUA cells were examined. As shown in Fig. 1A, four cytokines, with the exception of IL-11, stimulated the cell proliferation of HHUA cells in a dose-dependent manner. IL-11 did not demonstrate any effects on cell proliferation. Co-stimulatory effects with the cytokines and anti-Fas IgM on the cell viability of the HHUA cells were also examined (Fig. 1B). All five of the STAT3-activating cytokines, including IL-11, significantly enhanced Fas-stimulated cell death in HHUA cells.

Effects of STAT3-activating cytokines on Fas-mediated DNA fragmentation and cell surface Fas antigen expression in HHUA cells. To confirm that the five STAT3-activating cytokines enhanced Fas-stimulated apoptosis in HHUA cells, DNA fragmentation assays were performed. As shown in Fig. 2A, the addition of the STAT3-activating cytokines apparently enhanced anti-Fas IgM-stimulated DNA fragmentation in HHUA cells. To examine whether the five STAT3-activating cytokines stimulated cell surface Fas antigen expression to enhance apoptosis in HHUA cells, semi-quantitative flow cytometric assays were carried out on the cytokine-treated HHUA cells. Flow cytometric experiments showed that five STAT3-activating cytokines did not apparently stimulate cell surface Fas antigen expression on HHUA cells (Fig. 2B).

Effects of STAT3 siRNA transfection on Fas-mediated cell death of HHUA cells. To clarify whether the enhancement of Fas-mediated apoptotic signals by five cytokines was due to activation of the STAT3 signaling pathway, targeted knockdown of STAT3 in HHUA cells was performed. STAT3 siRNA transfection into HHUA cells suppressed STAT3 protein expression (Fig. 3A); however, no changes in proliferation and cell viability were apparent by microscopic observations (Fig. 3B). STAT3 siRNA transfection, however, significantly enhanced the cell viability of HHUA cells treated with anti-Fas IgM (Fig. 3C).

\section{Discussion}

The present study demonstrates that five STAT3-activating cytokines enhance Fas-stimulated apoptotic susceptibility in HHUA human endometrial epithelial cells. HHUA cells do not express any Fas ligand mRNA (20), and the five STAT3activating cytokines do not stimulate cell surface Fas antigen 


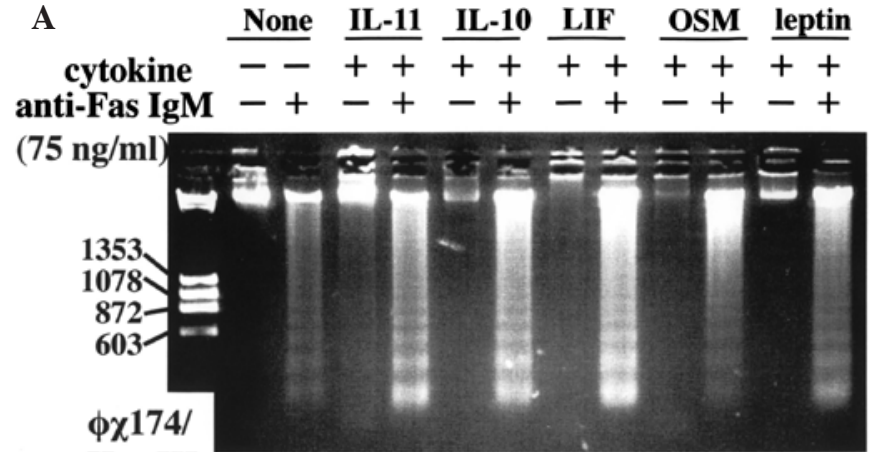

Hae III

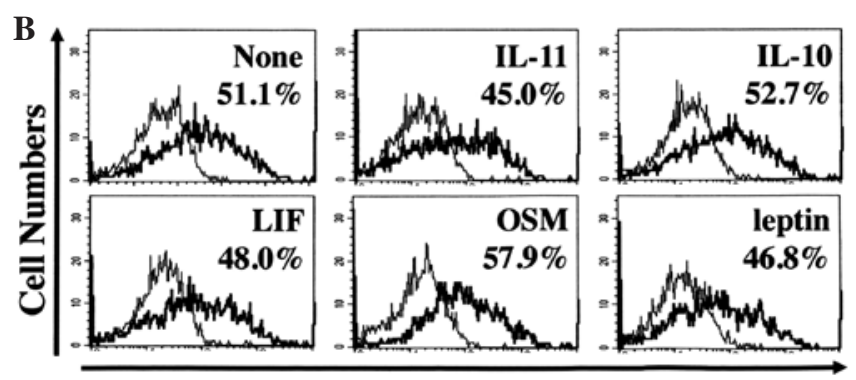

Fluorescence Intensity (log)

Figure 2. Effects of STAT3-activating cytokines on Fas-mediated DNA fragmentation and cell surface Fas antigen expression in HHUA cells. (A) Effects of STAT3-activating cytokines on Fas-mediated DNA fragmentation in HHUA cells. DNA extracted from HHUA cells co-stimulated with $75 \mathrm{ng} /$ $\mathrm{ml}$ of anti-Fas IgM and one of the STAT3-activating cytokines were analyzed by DNA fragmentation assays. The final concentrations of the recombinant human cytokines in culture media were $100 \mathrm{ng} / \mathrm{ml}$ for IL-11, IL-10, LIF and OSM, and $200 \mathrm{ng} / \mathrm{ml}$ for leptin. (B) Quantitative flow cytometric analyses of cell surface Fas-antigen expression levels on HHUA cells treated with five STAT3-activating cytokines. HHUA cells were pre-treated for $48 \mathrm{~h}$ with each STAT3-activating cytokine. The final concentrations of the recombinant human cytokines in culture media were $100 \mathrm{ng} / \mathrm{ml}$ for IL-11, IL-10, LIF and OSM, and $200 \mathrm{ng} / \mathrm{ml}$ for leptin. The thick lines indicate Fas expression and the thin lines indicate negative controls. Positivity was calculated as the positive area $(\%)$ of Fas expression against a control area.

expression on HHUA cells. These results indicate that STAT3 activation enhances intracellular signals of Fas-mediated apoptosis. In the absence of STAT3-activating cytokines, specific knockdown of STAT3 expression by STAT3 siRNA transfection significantly inhibits the Fas-mediated apoptosis of HHUA cells, suggesting that STAT3-activating signals constitutively enhance Fas-mediated intracellular apoptotic signals in HHUA cells. In conclusion, the intracellular apoptotic signals in HHUA cells can be constitutively activated and regulated by STAT3-mediated signals.

There are many reports demonstrating that STAT3 activation plays anti-apoptotic roles in various cancer cells, including glioblastoma stem cells (21), glioma cells (22), prostate cancer cells (23), laryngeal cancer cells (24), cholangiocarcinoma cells (25), esophageal adenocarcinoma cells (26), gastric cancer cells (27), myeloid leukemia cells (28) and T-cell lymphoma cells (29). The anti-apoptotic functions of STAT3 signals are also reported in non-tumor cells, such as proximal renal tubular epithelial cells (30) and bronchial epithelial cells (31). Inhibition of STAT3 signals is reported to enhance radiosensitivity in squamous cell carcinoma cells (32), laryngeal cancer cells (33) and glioma cells (34), suggesting that STAT3 acti-
A

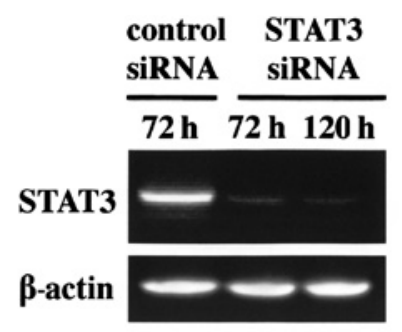

B

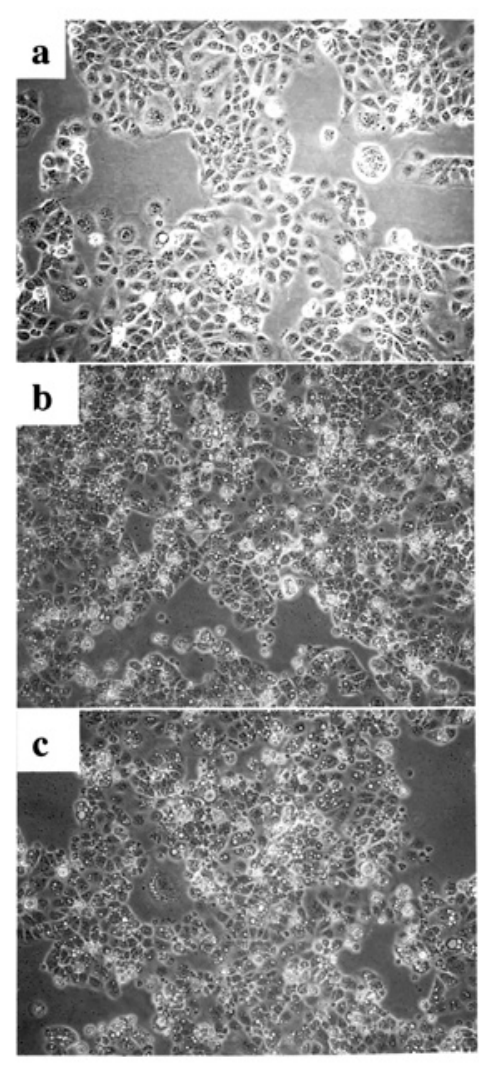

C

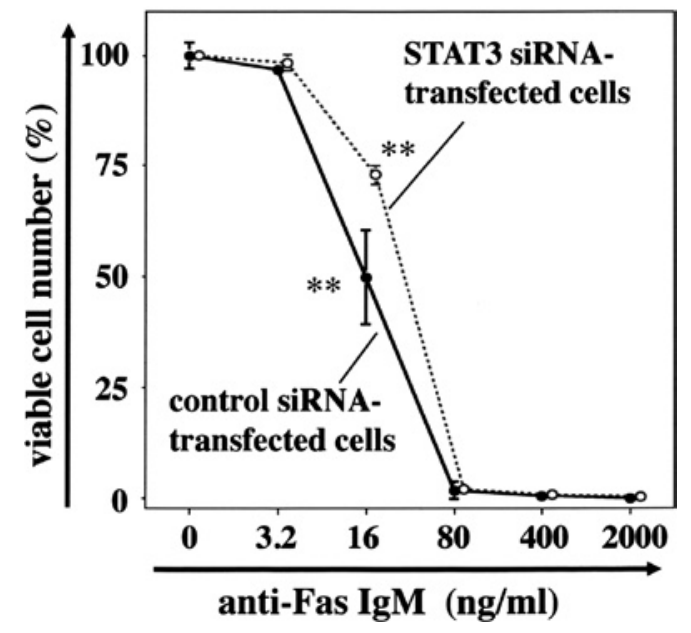

Figure 3. The effects of targeted knockdown of STAT3 expression by STAT3 siRNA transfection into HHUA cells on cell proliferation and Fas-mediated apoptosis. (A) Western blot analysis of HHUA cells transfected with siRNAs. STAT3 protein expression was strongly inhibited $72 \mathrm{~h}$ after siRNA transfection, while $\beta$-actin expression was not affected at all. (B) Phase contrast microscope views of the HHUA cells. a, untreated HHUA cells; b, HHUA cells treated with control siRNA for $48 \mathrm{~h}$; c, HHUA cells treated with STAT3 siRNA for $48 \mathrm{~h}$. Targeted knockdown of STAT3 in the HHUA cells did not alter the proliferation of the cells compared to cells transfected with the control siRNA. (C) Fas-mediated apoptosis was significantly inhibited in the STAT3 siRNA-transfected HHUA cells. ${ }^{* *} \mathrm{p}<0.01$. 
vation enhances cell survival against radiation cell death. As for Fas-mediated apoptosis, it has been reported that STAT3siRNA induces Fas-mediated apoptosis in vitro and in vivo in breast cancer cells (35). To the best of our knowledge, there have been no previous reports stating that STAT3 activation enhances apoptosis in any cells. Our present study may be the first to report that STAT3 activation enhances intracellular apoptotic signals. This exceptional phenomenon in HHUA cells may be caused by the specific lineage of HHUA cells.

Five STAT3-activating cytokines were used in the present experiments. Although IL-10, leptin, LIF and OSM dose-dependently simulated the cell proliferation of the HHUA cells, IL-11 did not affect cell proliferation at all. IL-11 enhanced the Fas-mediated apoptosis of the HHUA cells. Targeted knockdown of STAT3 expression by STAT3-siRNA treatment has previously been reported to inhibit the cell proliferation of various cells, including prostate cancer cells (23), laryngeal cancer cells (24), cutaneous squamous cell carcinomas (36), multiple myeloma cells (37), hepatocellular carcinoma cells (38) and glioma cells (39). However, there have been no reports indicating that STAT3 activation inhibits the proliferation of any cells. The growth-promoting effects by four STAT3-activating cytokines in HHUA cells coincided with previous reports that STAT3-activated signals enhanced cell proliferation. It is unknown why IL-11 did not stimulate the proliferation of HHUA cells. Our previous study demonstrated that epidermal growth factor (EGF), a STAT3-activating cytokine, enhanced Fas-mediated apoptosis, while EGF did not enhance cell proliferation or cell surface Fas expression in HHUA cells (40). The effects of IL-11 in the present study coincide with the effects of the EGF on HHUA cells.

Normal human endometrial epithelial cells play cell lineage-specific physiological roles in blastocyst implantation. When the blastocyst is implanted into the endometrium, endometrial epithelial cells become apoptotic to accept blastocyst invasion, and then endometrial epithelial cells proliferate to cover the invaded blastocyst. Increased apoptotic susceptibility and growth-promoting activity of endometrial epithelial cells during blastocyst implantation may reflect the results that apoptotic susceptibility and cell proliferation were enhanced by STAT3-activating cytokines in HHUA cells. Both IL-11 and LIF are essential STAT3-activating cytokines for blastocyst implantation $(11,12)$. Since HHUA are not normal cells, even though the cells have several characteristics of normal human endometrial epithelial cells, further investigations using normal endometrial cells are required to conclude that the STAT3-mediated effects observed on HHUA cell function during blastocyst implantation in the normal endometrium are indeed genuine.

\section{References}

1. Otsuki Y, Misaki O, Sugimoto O, Ito Y, Tsujimoto Y and Akao Y: Cyclic Bcl-2 gene expression in human uterine endometrium during menstrual cycle. Lancet 344: 28-29, 1994.

2. Tabibzadeh S: Signals and molecular pathways involved in apoptosis with special emphasis on human endometrium. Hum Reprod Update 1: 303-323, 1995.

3. Watanabe $\mathrm{H}$, Kanzaki H, Narukawa S, Inoue T, Katsuragawa $H$, Kaneko Y and Mori T: Bcl-2 and Fas expression in eutopic and ectopic human endometrium during the menstrual cycle in relation to endometrial cell apoptosis. Am J Obstet Gynecol 176 360-368, 1997.
4. Selam B, Kayisli UA, Mulayim N and Arici A: Regulation of Fas ligand expression by estradiol and progesterone in human endometrium. Biol Reprod 65: 979-985, 2001.

5. Song J, Rutherford T, Naftolin F, Brown S and Mor G: Hormonal regulation of apoptosis and the Fas and Fas ligand system in human endometrial cells. Mol Hum Reprod 8: 447-455, 2002.

6. Abe H, Shibata MA and Otsuki Y: Caspase cascade of Fas-mediated apoptosis in human normal endometrium and endometrial carcinoma cells. Mol Hum Reprod 12: 535-541, 2006.

7. Kamijo T, Rajabi MR, Mizunuma H and Ibuki Y: Biochemical evidence for autocrine/paracrine regulation of apoptosis in cultured uterine epithelial cells during mouse embryo implantantion in vitro. Mol Hum Reprod 4: 990-993, 1998.

8. Galán A, O'Connor JE, Valbuena D, Herrer R, Remohí J, Pampfer S, Pellicer A and Simón C: The human blastocyst regulates endometrial epithelial apoptosis in embryonic adhesion. Biol Reprod 63: 430-439, 2000.

9. Tanaka $\mathrm{T}$ and Umesaki N: Cytokine regulation of apoptotic susceptibility in a human endometrial epithelial cell line. J Reprod Immunol 47: 105-119, 2000.

10. Atasoy P, Bozdoğan O, Erekul S, Bozdoğan N and Bayram M: Fas-mediated pathway and apoptosis in normal, hyperplastic, and neoplastic endometrium. Gynecol Oncol 91: 309-317, 2003.

11. Stewart CL, Kaspar P, Brunet LJ, Bhatt H, Gadi I, Kontgen F and Abbondanzo SJ: Blastocyst implantation depends on maternal expression of leukaemia inhibitory factor. Nature 359: 76-79, 1992.

12. Robb L, Li R, Hartley L, Nandurkar HH, Koentgen F and Begley CG: Infertility in female mice lacking the receptor for interleukin 11 is due to a defective uterine response to implantation. Nat Med 4: 303-308, 1998.

13. Tanaka T and Umesaki N: Oncostatin M inhibits decidualization of normal human endometrial stromal cells. Int J Mol Med 11: 627-630, 2003.

14. Catalano RD, Johnson MH, Campbell EA, Charnock-Jones DS, Smith SK and Sharkey AM: Inhibition of Stat3 activation in the endometrium prevents implantation: a nonsteroidal approach to contraception. Proc Natl Acad Sci USA 102: 8585-8590, 2005.

15. Yoon SJ, Cha KY and Lee KA: Leptin receptors are down-regulated in uterine implantation sites compared to interimplantation sites. Mol Cell Endocrinol 232: 27-35, 2005.

16. White CA, Johansson M, Roberts CT, Ramsay AJ and Robertson SA: Effect of interleukin-10 null mutation on maternal immune response and reproductive outcome in mice. Biol Reprod 70: 123-131, 2004.

17. Ishiwata I, Ishiwata C, Soma M, Arai J and Ishikawa H: Establishment of human endometrial adenocarcinoma cell line containing estradiol-17 beta and progesteron receptors. Gynecol Onc 17: 281-290, 1984.

18. Mikami M, Sakai K, Yoshiki J, et al: Differentiation of endometrial carcinoma cell lines cultured in type 1 collagen gel and significance of sulfate lipid. Acta Obstet Gynecol Jpn 48: S348, 1996.

19. Tanaka T, Bai T and Toujima S: Establishment and characterization of monoclonal 5-fluorouracil-resistant cell lines derived from human endometrial adenocarcinoma. Int $\mathrm{J}$ Oncol 37: 731-736, 2010.

20. Bai T, Tanaka T and Yukawa K: Targeted knockdown of deathassociated protein kinase expression induces TRAIL-mediated apoptosis in human endometrial adenocarcinoma cells. Int $\mathbf{J}$ Oncol 37: 203-210, 2010.

21. Li GH, Wei H, Lv SQ, Ji H and Wang DL: Knockdown of STAT3 expression by RNAi suppresses growth and induces apoptosis and differentiation in glioblastoma stem cells. Int J Oncol 37: 103-110, 2010.

22. Chen F, Xu Y, Luo Y, et al: Down-regulation of Stat3 decreases invasion activity and induces apoptosis of human glioma cells. J Mol Neurosci 40: 353-359, 2010.

23. Lee SO, Lou W, Qureshi KM, Mehraein-Ghomi F, Trump DL and Gao AC: RNA interference targeting Stat3 inhibits growth and induces apoptosis of human prostate cancer cells. Prostate 60: 303-309, 2004.

24. Gao LF, Xu DQ, Wen LJ, Zhang XY, Shao YT and Zhao XJ: Inhibition of STAT3 expression by siRNA suppresses growth and induces apoptosis in laryngeal cancer cells. Acta Pharmacol Sci 26: 377-383, 2005.

25. Blechacz BR, Smoot RL, Bronk SF, Werneburg NW, Sirica AE and Gores GJ: Sorafenib inhibits signal transducer and activator of transcription-3 signaling in cholangiocarcinoma cells by activating the phosphatase shatterproof 2. Hepatology 50: 1861-1870, 2009. 
26. Beales IL and Ogunwobi OO: Glycine-extended gastrin inhibits apoptosis in Barrett's oesophageal and oesophageal adenocarcinoma cells through JAK2/STAT3 activation. J Mol Endocrinol 42: 305-318, 2009.

27. Sekikawa A, Fukui H, Fujii S, et al: REG Ialpha protein mediates an anti-apoptotic effect of STAT3 signaling in gastric cancer cells. Carcinogenesis 29: 76-83, 2008.

28. Ma LD, Zhou M, Wen SH, Ni C, Jiang LJ, Fan J and Xia L: Effects of STAT3 silencing on fate of chronic myelogenous leukemia K562 cells. Leuk Lymphoma 51: 1326-1336, 2010.

29. Verma NK, Davies AM, Long A, Kelleher D and Volkov Y: STAT3 knockdown by siRNA induces apoptosis in human cutaneous T-cell lymphoma line Hut78 via downregulation of Bcl-xL. Cell Mol Biol Lett 15: 342-355, 2010.

30. Wang J, Ouyang C, Chen X, Fu B, Lu Y and Hong Q: STAT3 inhibits apoptosis of human renal tubular epithelial cells induced by ATP depletion/recovery. Nephron Exp Nephrol 108: e11-e18, 2008.

31. Liu X: STAT3 activation inhibits human bronchial epithelial cell apoptosis in response to cigarette smoke exposure. Biochem Biophys Res Commun 353: 121-126, 2007.

32. Bonner JA, Trummell HQ, Willey CD, Plants BA and Raisch KP: Inhibition of STAT-3 results in radiosensitization of human squamous cell carcinoma. Radiother Oncol 92: 339-344, 2009.

33. Li X, Wang H, Lu X and Di B: STAT3 blockade with shRNA enhances radiosensitivity in Hep-2 human laryngeal squamous carcinoma cells. Oncol Rep 23: 345-353, 2010.
34. Gao L, Li F, Dong B, et al: Inhibition of STAT3 and ErbB2 suppresses tumor growth, enhances radiosensitivity, and induces mitochondria-dependent apoptosis in glioma cells. Int J Radiat Oncol Biol Phys 77: 1223-1231, 2010.

35. Kunigal S, Lakka SS, Sodadasu PK, Estes N and Rao JS: Stat3siRNA induces Fas-mediated apoptosis in vitro and in vivo in breast cancer. Int J Oncol 34: 1209-1220, 2009.

36. Sumita N, Bito T, Nakajima K and Nishigori C: Stat3 activation is required for cell proliferation and tumorigenesis but not for cell viability in cutaneous squamous cell carcinoma cell lines. Exp Dermatol 15: 291-299, 2006.

37. Pathak AK, Bhutani M, Nair AS, Ahn KS, Chakraborty A, Kadara H, Guha S, Sethi G and Aggarwal BB: Ursolic acid inhibits STAT3 activation pathway leading to suppression of proliferation and chemosensitization of human multiple myeloma cells. Mol Cancer Res 5: 943-945, 2007.

38. Li J, Piao YF, Jiang Z, Chen L and Sun HB: Silencing of signal transducer and activator of transcription 3 expression by RNA interference suppresses growth of human hepatocellular carcinoma in tumor-bearing nude mice. World J Gastroenterol 15: 2602-2608, 2009.

39. Gao L, Li F, Dong B, et al: Inhibition of STAT3 and ErbB2 suppresses tumor growth, enhances radiosensitivity, and induces mitochondria-dependent apoptosis in glioma cells. Int J Radiat Oncol Biol Phys 77: 1223-1231, 2010.

40. Tanaka T, Mizuno K, Miyama M, et al: Enhanced Fas/CD95mediated apoptosis by epidermal growth factor in human endometrial epithelial cells. Eur J Obstet Gynecol Reprod Biol 86: 189-194, 1999 